\title{
Homogeneous Catalysis
}

\section{Pt"-Catalyzed Hydroxylation of Terminal Aliphatic $\mathrm{C}\left(\mathrm{sp}^{3}\right)-\mathrm{H}$ Bonds with Molecular Oxygen}

\author{
Michiel Janssen and Dirk E. De Vos*[a]
}

Abstract: The practical application of Shilov-type Pt catalysis to the selective hydroxylation of terminal aliphatic $\mathrm{C}-\mathrm{H}$ bonds remains a formidable challenge, due to difficulties in replacing $\mathrm{Pt}^{\mathrm{IV}}$ with a more economically viable oxidant, particularly $\mathrm{O}_{2}$. We report the potential of employing $\mathrm{FeCl}_{2}$ as a suitable redox mediator to overcome the kinetic hurdles related to the direct use of $\mathrm{O}_{2}$ in the Pt reoxidation. For the selective conversion of butyric acid to $\gamma$-hydroxybutyric acid (GHB), a significantly enhanced catalyst activity and stability (turnover numbers $(T O N)>30$ ) were achieved under 20 bar $\mathrm{O}_{2}$ in comparison to current state-of-the-art systems (TON < 10). In this regard, essential reaction parameters affecting the overall activity were identified, along with specific addi- tives to attain catalyst stability at longer reaction times. Notably, deactivation by reduction to $\mathrm{Pt}^{0}$ was prevented by the addition of monodentate pyridine derivatives, such as 2-fluoropyridine, but also by introducing varying partial pressures of $\mathrm{N}_{2}$ in the gaseous atmosphere. Finally, stability tests revealed the involvement of $\mathrm{Pt}^{\prime \prime}$ and $\mathrm{FeCl}_{2}$ in catalyzing the non-selective overoxidation of GHB. Accordingly, in situ esterification with boric acid proved to be a suitable strategy to maintain enhanced selectivities at much higher conversions (TON > 60). Altogether, a useful catalytic system for the selective hydroxylation of primary aliphatic $\mathrm{C}-\mathrm{H}$ bonds with $\mathrm{O}_{2}$ is presented.

\section{Introduction}

The oxidation of saturated aliphatic $\mathrm{C}-\mathrm{H}$ bonds is a powerful tool to obtain useful oxygenated functionalities in otherwise inert organic compounds, thereby uncovering their potential as valuable starting materials. ${ }^{[1,2]}$ An attractive route comprises the site-selective hydroxylation of terminal $\mathrm{C}-\mathrm{H}$ bonds, not only because it involves favorable thermodynamics and a high atom economy, but also because the resulting primary alcohol is of prime importance in industrial applications. ${ }^{[3-5]}$ Nevertheless, this reaction still represents a tremendous challenge in modern organic chemistry, due to the chemical inertness of saturated hydrocarbons. Therefore, prevailing systems use harsh radical-mediated pathways that are incompatible with both chemo- and regioselective transformations. More specifically, as the reactivity in such pathways is dictated by the homolytic $\mathrm{C}-\mathrm{H}$ bond dissociation energy, which decreases in the order of primary $>$ secondary $>$ tertiary $\mathrm{C}-\mathrm{H}$ bonds, terminal functionalization of the aliphatic chain is less favored. In addition, more advanced oxidation levels are commonly observed, owing to

[a] M. Janssen, Prof. D. E. De Vos

Centre for Membrane separations, Adsorption, Catalysis and Spectroscopy for Sustainable Solutions (CMACS)

KU Leuven

Celestijnenlaan 200F, P.O. Box 2454

3001 Leuven (Belgium)

E-mail:dirk.devos@kuleuven.be

$\square$ Supporting Information and the ORCID identification numbers for some of

(iD the authors of this article are available on the WWW under https://doi.org/10.1002/chem.201901803. the higher reactivity of the alcohol product relative to the alkane substrate. ${ }^{[6,7]}$

To favor the formation of the (primary) alcohol product, fundamentally different activation modes are needed. ${ }^{[8]} \mathrm{A}$ considerable amount of research has therefore been devoted to the use of electrophilic late transition metals in a variety of protic solvents. ${ }^{[9,10]}$ This particular interest in electrophilic $\mathrm{C}-\mathrm{H}$ activation is based on earlier observations of the Pt"-mediated H/D exchange of arenes in acidic aqueous solutions. ${ }^{[11]}$ In fact, by incorporating $\mathrm{Pt}^{\mathrm{IV}}$ as a stoichiometric oxidant, Shilov and coworkers successfully extended the intermolecular $\mathrm{C}-\mathrm{H}$ activation step to a true functionalization reaction (Scheme 1). ${ }^{[12,13]}$ More importantly, the intrinsic value of this Shilov system originates from its unique selectivity pattern; using Pt" significantly

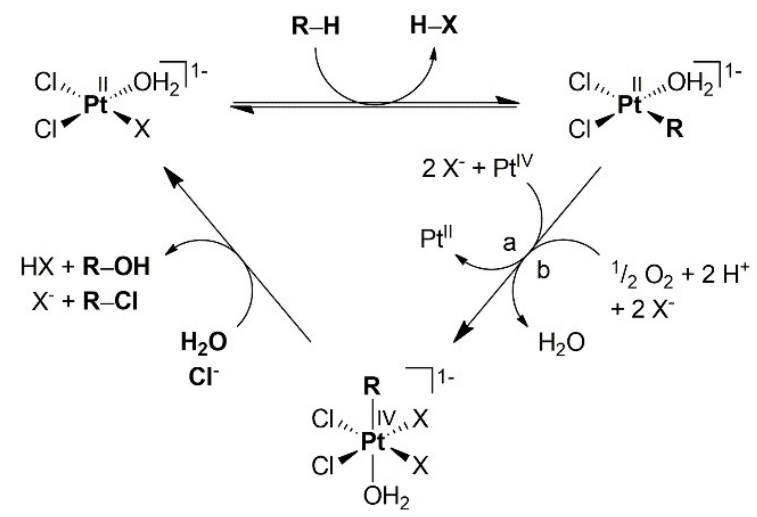

Scheme 1. Catalytic cycle for the Shilov system with a) Pt ${ }^{\mathrm{IV}}$ and b) molecular oxygen $\left(\mathrm{O}_{2}\right)$ as the terminal oxidant. ${ }^{[1]}$ 
reduces the extent of overoxidation and, as a result, directs the oxidative transformation towards selective hydroxylation. In a similar way, Pt discriminates between non-equivalent $\mathrm{C}-\mathrm{H}$ bonds in a very different manner than radicals do, giving rise to an enhanced reactivity of the terminal $\mathrm{C}-\mathrm{H}$ bonds. ${ }^{\left[{ }^{[1,14]}\right.}$ Moreover, a complete reversal in regioselectivity was reported for the remote oxidation of mono-functionalized organic compounds, which has been attributed to a "chelate effect". ${ }^{[15 a, c]}$ In particular, Sen and co-workers observed the following order of reactivity: $\alpha-\mathrm{C}-\mathrm{H} \ll \beta-\mathrm{C}-\mathrm{H}<\gamma-\mathrm{C}-\mathrm{H}<\delta-\mathrm{C}-\mathrm{H}$ for alcohols and $\alpha-$ $\mathrm{C}-\mathrm{H} \ll \beta-\mathrm{C}-\mathrm{H}<\gamma-\mathrm{C}-\mathrm{H} \geq \delta-\mathrm{C}-\mathrm{H}$ for carboxylic, sulfonic and phosphonic acids. ${ }^{[15]}$ Based on these trends, it was suggested that a metallocyclic intermediate forms upon coordination of the functional group to the electrophilic Pt" center, in which the $\mathrm{C}-\mathrm{H}$ bond reactivity is determined by the ring strain. ${ }^{[15 c]}$

Nonetheless, the inherently low turnover numbers (TON, $<1$ ) and turnover frequencies (TOF, $<0.004 \mathrm{~h}^{-1}$ ), in combination with the need for stoichiometric quantities of an expensive $\mathrm{Pt}^{\mathrm{IV}}$ salt, ${ }^{[15 a, c]}$ render this system impractical in large-scale applications. ${ }^{[3]}$ Earlier mechanistic studies fortunately confirmed that the oxidation step (Scheme 1) does not proceed by an alkyl transfer, but instead requires an inner-sphere two-electron transfer from $\mathrm{Pt}^{\mathrm{I}}-\mathrm{R}$ to $\mathrm{Pt}^{\mathrm{IV}} .^{[1]}$ Accordingly, these findings revealed the possibility of replacing $\mathrm{Pt}^{\mathrm{lV}}$ with a more economical and readily available oxidant. Although equivalent amounts of $\mathrm{CuCl}_{2}$ have hitherto been applied with moderate success, ${ }^{[16,17]}$ using dioxygen $\left(\mathrm{O}_{2}\right)$ would offer major opportunities from an industrial and ecological perspective. ${ }^{[18]}$ Applying $\mathrm{O}_{2}$ as sole terminal oxidant is however known to impose a kinetic limitation on the overall reaction, causing rapid deactivation of the Pt catalyst by reduction to metallic platinum. ${ }^{[1,10,19]}$ To ensure a more efficient electron transfer chain between $\mathrm{Pt}^{\prime \prime}$ and $\mathrm{O}_{2}$, together with a faster reoxidation of possibly formed $\mathrm{Pt}^{0}$, the addition of a redox mediator was originally proposed by Gol'dshlger et al. ${ }^{[20]}$ Even though $\mathrm{Cu}^{\prime \prime}, \mathrm{Fe}^{\mathrm{III}}$ and certain heteropolyacids, ${ }^{[20-25]}$ for example, $\mathrm{H}_{5} \mathrm{PV}_{2} \mathrm{Mo}_{10} \mathrm{O}_{40}{ }^{[25]}$ have proven to be reasonably efficient in activating $\mathrm{O}_{2}$, proper systems that combine a sufficiently active and stable catalyst with high alcohol and terminal selectivity remain elusive.

In this work, the ability of $\mathrm{FeCl}_{2}$ to generate a highly active and durable Pt catalyst for the regioselective hydroxylation of butyric acid to $\gamma$-hydroxybutyric acid (GHB) with $\mathrm{O}_{2}$ is successfully illustrated. Moreover, a more profound understanding is provided concerning those experimental parameters that determine the overall activity of the catalytic system, together with the specific role of nitrogen-containing additives in prolonging the catalyst stability. Ultimately, a reaction network is proposed for the overoxidation of GHB, and suitable strategies are evaluated to counteract these non-selective side reactions.

\section{Results and Discussion}

\section{Pt-related characteristics of remote aliphatic $\mathrm{C}-\mathrm{H}$ oxidation}

Despite the fact that water is one of the few reaction media that is fully stable under oxidative conditions, its use in $\mathrm{C}-\mathrm{H}$ activation processes was initially considered ineffective. It was believed that the preferential solvation of the metal center with water would hinder coordination of the aliphatic substrate and elicit hydrolysis of the resulting metal-alkyl species. ${ }^{[9]}$ Nevertheless, by implementing a simple Pt" catalyst, Shilov and co-workers ${ }^{[12]}$ were the first to demonstrate the potential of using acidic aqueous media in the field of selective $\mathrm{C}-\mathrm{H}$ functionalization. To illustrate this unique property of $\mathrm{Pt}^{\mathrm{\prime}}$, the activity of $\mathrm{K}_{2} \mathrm{PtCl}_{4}$ was compared to that of a $\mathrm{Pd}$ - and $\mathrm{Ni}$ based catalyst, by measuring the conversion of butyric acid in an acidified aqueous solution $\left(0.33 \mathrm{M} \mathrm{H}_{2} \mathrm{SO}_{4}\right)$ upon reaction for $6 \mathrm{~h}$ at $150^{\circ} \mathrm{C}$ under 20 bar $\mathrm{O}_{2}$ (Table 1 ). Butyric acid was chosen

\begin{tabular}{|c|c|c|c|c|c|c|c|}
\hline \multirow[t]{2}{*}{ Catalyst } & \multirow[t]{2}{*}{$\mathrm{X}[\%]$} & \multirow[t]{2}{*}{ S [\%] } & \multicolumn{5}{|c|}{ Carbon yield [\%] ${ }^{[b]}$} \\
\hline & & & GHB & $\mathrm{BHB}$ & $\mathrm{AHB}$ & SA & $\mathrm{DP}^{[c]}$ \\
\hline- & 0.7 & 0 & 0 & 0 & 0.1 & 0 & 0.6 \\
\hline $\mathrm{K}_{2} \mathrm{PtCl}_{4}$ & 75.4 & 25 & 19.0 & 1.5 & 1.2 & 1.3 & 52.4 \\
\hline $\mathrm{PdCl}_{2}$ & 17.5 & 17 & 3 & 0.2 & 0.2 & 0.4 & 13.7 \\
\hline $\mathrm{NiCl}_{2}$ & 2.5 & 0 & 0 & 0 & 0 & 0 & 2.5 \\
\hline
\end{tabular}

[a] Conditions: butyric acid $(0.67 \mathrm{M})$, catalyst $(1 \mathrm{~mol} \%), \mathrm{H}_{2} \mathrm{SO}_{4}(0.33 \mathrm{M})$, $\mathrm{CuCl}_{2} \cdot 2 \mathrm{H}_{2} \mathrm{O}(5 \mathrm{~mol} \%), \mathrm{H}_{2} \mathrm{O}(1.5 \mathrm{~mL}), 6 \mathrm{~h}, 150^{\circ} \mathrm{C}, 20$ bar $\mathrm{O}_{2} . \mathrm{GHB}=\gamma$-hydroxybutyric acid, $\mathrm{BHB}=\beta$-hydroxybutyric acid, $\mathrm{AHB}=\alpha$-hydroxybutyric acid, $\mathrm{SA}=$ succinic acid, $\mathrm{DP}=$ degradation products. [b] Number of mmoles of $C$ in the corresponding product divided by the total mmoles of $C$ initially supplied in butyric acid $(4 \mathrm{mmol})$. [c] Lower degradation products include lactic acid, acetone, acetic acid, glycolic acid, acetaldehyde, formic acid, methanol and gaseous compounds.

as cheap and abundant substrate, since selective hydroxylation at $-\mathrm{CH}_{3}$ is a promising route towards GHB and $\gamma$-butyrolactone $(\mathrm{GBL})$, both of which are extensively used in industry, for example as major industrial solvent, for medical purposes (treatment of narcolepsy) and as precursor in the chemical synthesis of pyrrolidones and biodegradable polyhydroxyalkanoates. ${ }^{[26]}$ Moreover, its molecular structure promotes a chelating effect; a six-membered ring with minimal ring strain can form upon coordination of the carboxylic acid group to Pt", favoring remote $\mathrm{C}-\mathrm{H}$ activation (Scheme 2). ${ }^{[15 a, c]}$ By analogy with the work of $\mathrm{Lin}$ et al., ${ }^{[21]} \mathrm{CuCl}_{2}$ was included as co-catalyst to ensure proper comparison of the catalyst activity.

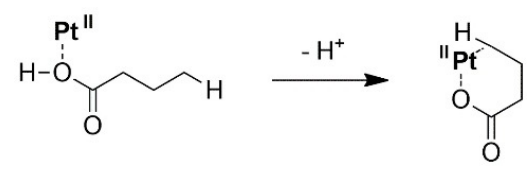

Scheme 2. Chelate effect upon coordination of butyric acid to $\mathrm{Pt}{ }^{11} .{ }^{15 c]}$

As expected, substantial conversion of butyric acid $(X=$ $75 \%$ ) was only observed in the presence of $\mathrm{K}_{2} \mathrm{PtCl}_{4}$ (Table 1, entry 2), thereby confirming the specific role of $\mathrm{Pt}^{\prime \prime}$ in activating terminal aliphatic $\mathrm{C}-\mathrm{H}$ bonds in protic aqueous solutions. The selectivity (S) towards GHB was, however, limited to $25 \%$ due to extensive overoxidation. Accordingly, a comprehensive 
qualitative analysis by $1 \mathrm{D}$ and 2D NMR revealed the formation of succinic acid in combination with multiple lower degradation products, such as acetic acid, glycolic acid and formic acid (see the Supporting Information, Figures S1-4). In addition, various gaseous compounds, primarily $\mathrm{CO}_{2}$ and to a minor extent $\mathrm{CO}$ and $\mathrm{CH}_{4}$, were detected by quantitative infrared spectroscopy. These results contrast with those reported by Lin et al., ${ }^{[21]}$ who stated that no $\mathrm{C}-\mathrm{C}$ cleavage occurred during the oxidative transformation of short-chain carboxylic, sulfonic and phosphonic acids under similar or even more severe reaction conditions $\left(150^{\circ} \mathrm{C}, 90\right.$ bar $\left.\mathrm{O}_{2}\right)$.

\section{Co-catalyst screening}

Transition metal salts have proven successful as redox mediator in accelerating the Pt reoxidation by $\mathrm{O}_{2} \cdot{ }^{[20-22]}$ Nevertheless, only moderately active systems are available since research has hitherto been restricted to the use of $\mathrm{CuCl}_{2}$ and $\mathrm{FeCl}_{3} \cdot{ }^{[20-22]} \mathrm{A}$ more comprehensive screening of other transition metal salts was therefore performed based on the redox potential of the metal cation. ${ }^{[27]}$ Notably, a suitable redox mediator has to be able to oxidize the Pt"- $\mathrm{R}$ complex, but in turn has to be reoxidized by $\mathrm{O}_{2}$ as well. Hence, $\mathrm{Cu}, \mathrm{Re}, \mathrm{Mo}, \mathrm{Fe}, \mathrm{V}$ and $\mathrm{Mn}$ were evaluated in the transformation of butyric acid under 20 bar of $\mathrm{O}_{2}$. As illustrated in Figure 1, no clear correlation was found between the overall carbon yield and redox potential of the corresponding metal cation. However, replacing $\mathrm{CuCl}_{2}$ with $\mathrm{FeCl}_{2}$ led to a significantly increased catalytic activity, yielding $25 \%$ of GHB within $1 \mathrm{~h}$ with a selectivity of $76 \%$, which amounted to a TON (turnover number) of 33. In addition, only minor amounts of $\beta$-hydroxybutyric acid (BHB) and $\alpha$-hydroxybutyric acid (AHB) were observed, corresponding to a remarkable regioselectivity of $93 \%$ within the aliphatic chain. The proposed combination of $\mathrm{K}_{2} \mathrm{PtCl}_{4}$ and $\mathrm{FeCl}_{2} / \mathrm{O}_{2}$ thus clearly outperforms current state-of-the-art systems in the regioselective $\mathrm{C}-\mathrm{H}$ hydroxylation of butyric acid to GHB (Table 2).

Although the lower efficiency of $\mathrm{FeCl}_{3}$ compared to $\mathrm{CuCl}_{2}$ has already been reported, ${ }^{[22]}$ the above-mentioned effect of $\mathrm{FeCl}_{2}$ has not yet been seen before. The difference between $\mathrm{FeCl}_{2}$ and $\mathrm{FeCl}_{3}$ is striking, as the oxidizing species $\mathrm{Fe}^{\text {III }}$ could be assumed to be similar in both cases. To rationalize this dissimilarity, one must note that the tendency of Fe"ll to interact with one or more $\mathrm{Cl}^{-}$ions is quite high and even increases with temperature ${ }^{[30]}$ conversely, $\mathrm{FeCl}_{3}$ is not expected to dissociate to free $\mathrm{Fe}^{\mathrm{III}}$, but will occur as stable $\mathrm{FeCl}_{3},\left[\mathrm{FeCl}_{2}\right]^{+}$and/or $[\mathrm{FeCl}]^{2+}$ during the reaction. Also for the association of $\mathrm{Fe}^{\mathrm{III}}$ with sulfate, a very high equilibrium constant has been report$\mathrm{ed}^{[31]}$ suggesting that any free $\mathrm{Fe}^{\mathrm{III}}$ would be converted to $\mathrm{FeH}\left(\mathrm{SO}_{4}\right)_{2}$ or $\left[\mathrm{Fe}\left(\mathrm{SO}_{4}\right)_{2}\right]^{-}$in the reaction conditions, comprising $0.33 \mathrm{M} \mathrm{H}_{2} \mathrm{SO}_{4}$. On the other hand, association constants of $\mathrm{Fe}^{\mathrm{II}}$ with both $\mathrm{SO}_{4}{ }^{2-}$ and $\mathrm{Cl}^{-}$are small, ${ }^{[30,31]}$ meaning that when $\mathrm{FeCl}_{2}$ is used, there is initially a lot of free $\mathrm{Fe}^{\text {Il }}$ in solution. After oxidation of $\mathrm{Fe}^{\prime \prime}$ to $\mathrm{Fe}^{\mathrm{III}}$, the latter may partially associate with available $\mathrm{Cl}^{-}$ions to form stable complexes. Furthermore, with $\mathrm{CuCl}_{2}$ as alternative redox-active reagent, high chloride concentrations have proven to be beneficial for conversion, which has been explained in terms of a chlorine bridge formation be-

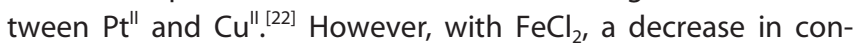
version occurred when $5 \mathrm{~mol} \%$ of an alkali metal halide, such as $\mathrm{NaCl}$, was added to the reaction mixture (Figure S5). Consequently, too high chloride concentrations might prevent the formation of a bridged Fe-Cl-Pt intermediate by saturating the

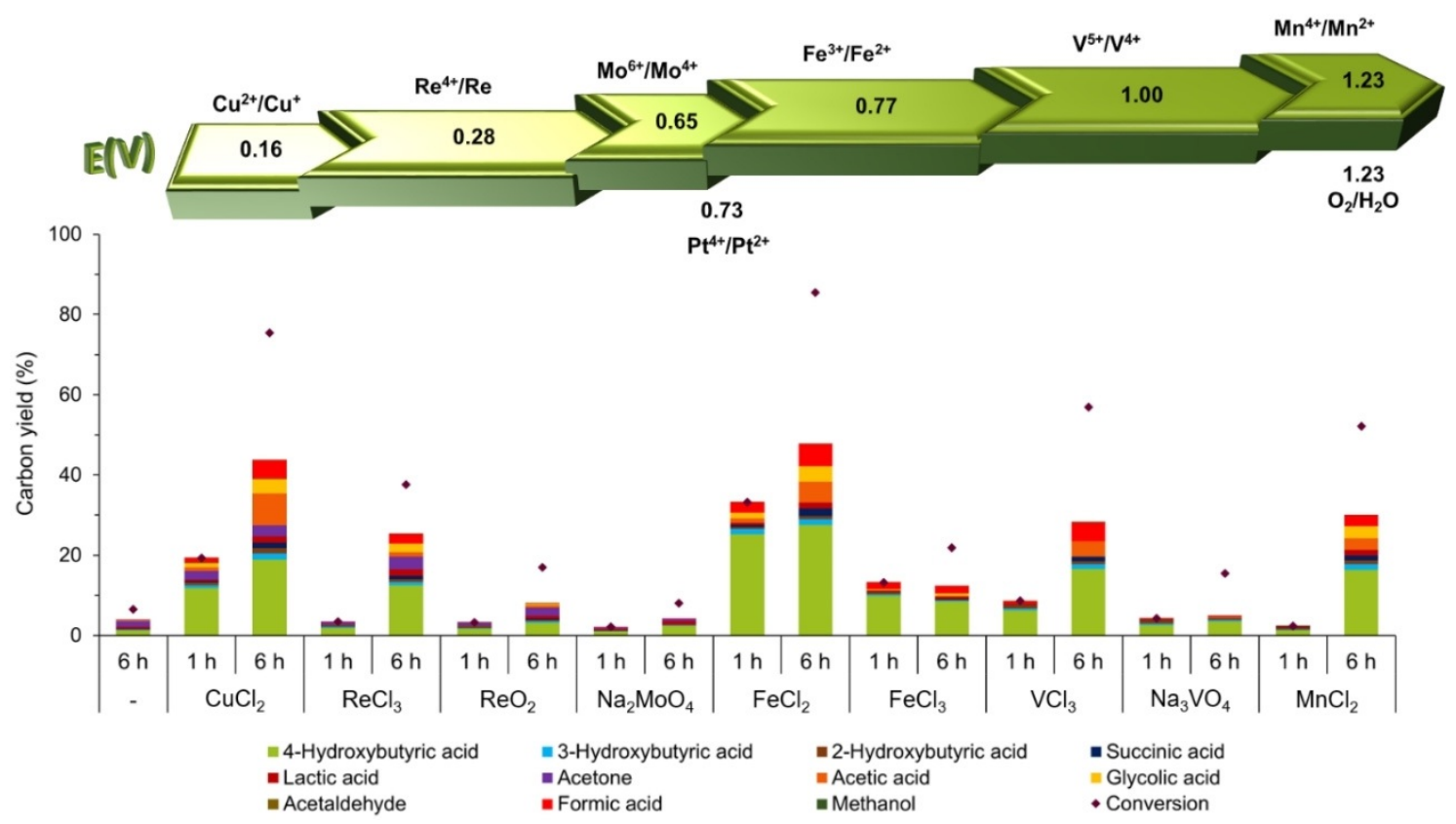

Figure 1. Influence of different transition metal salts on the Pt-catalyzed hydroxylation of butyric acid with $\mathrm{O}_{2}$, with illustration of their corresponding standard redox potential $\left(25^{\circ} \mathrm{C}, 1 \mathrm{~atm}, \mathrm{pH} 0\right)$ in $\mathrm{V}^{[27]}$ Conditions: butyric acid $(0.67 \mathrm{M}), \mathrm{K}_{2} \mathrm{PtCl}_{4}(1 \mathrm{~mol} \%), \mathrm{H}_{2} \mathrm{SO}_{4}(0.33 \mathrm{M}), \mathrm{co}-\mathrm{catalyst}(5 \mathrm{~mol} \%), \mathrm{H}_{2} \mathrm{O}(1.5 \mathrm{~mL}), 1-6 \mathrm{~h}$, $150^{\circ} \mathrm{C}, 20$ bar $\mathrm{O}_{2}$. 


\begin{tabular}{|c|c|c|c|c|c|c|c|}
\hline Catalyst & Oxidant & $\mathrm{T}\left[{ }^{\circ} \mathrm{C}\right]$ & TON & TOF $\left[h^{-1}\right]$ & $\mathrm{S}$ [\%] & PS $[\%]^{[f]}$ & Ref. \\
\hline $\mathrm{K}_{2} \mathrm{PtCl}_{4}^{\left[{ }^{[a]}\right.}$ & $\mathrm{FeCl}_{2} / \mathrm{O}_{2}$ & 150 & 33 & 33 & 76 & 93 & this work \\
\hline $\mathrm{K}_{2} \mathrm{PtCl}_{4}^{[\mathrm{b}]}$ & $\mathrm{K}_{2} \mathrm{PtCl}_{6}$ & $80-90$ & 0.24 & 0.0034 & 92 & 92 & [15a] \\
\hline $\mathrm{K}_{2} \mathrm{PtCl}_{4}^{\left[{ }^{[c]}\right.}$ & $\mathrm{K}_{2} \mathrm{PtCl}_{6}$ & $110-120$ & 0.52 & 0.0036 & 92 & 92 & {$[15 c]$} \\
\hline $\mathrm{CuCl}_{2}^{[\mathrm{d}]}$ & $\begin{array}{l}\mathrm{H}_{2} \mathrm{O}_{2} \text { (in situ formed by reaction of } \\
\mathrm{Pd}^{0} \text { with } \mathrm{CO} \text { and } \mathrm{O}_{2} \text { ) }\end{array}$ & 75 & 5.7 & 0.32 & 78 & 8.9 & [28] \\
\hline $\begin{array}{l}\text { tridentate NHC-amidate- } \\
\text { alkoxide Pd" complex }{ }^{\left[e^{[}\right]}\end{array}$ & $\mathrm{H}_{2} \mathrm{O}_{2} / \mathrm{AgBF}_{4}$ & 60 & no data & no data & 14 & 14 & [29] \\
\hline \multicolumn{8}{|c|}{ 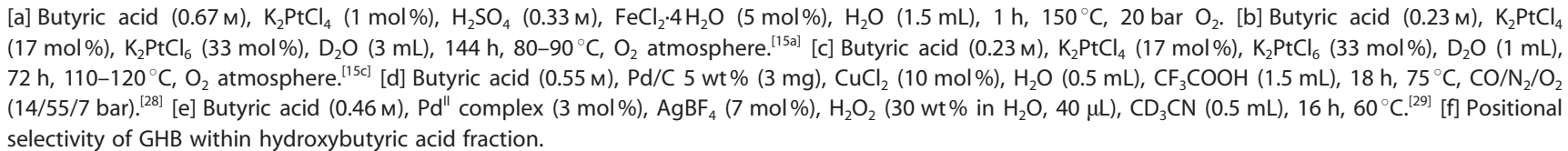 } \\
\hline
\end{tabular}

Fe co-catalyst or even the Pt catalyst. Moreover, halides typically increase the oxidation potential of the metal, which could slow down reoxidation of $\mathrm{Fe} \mathrm{e}^{\mathrm{I}}$ to its trivalent state. ${ }^{[30]}$ Additionally, the previously observed difference between $\mathrm{FeCl}_{2}$ and $\mathrm{FeCl}_{3}$ more or less disappeared upon replacing $\mathrm{Cl}^{-}$with weakly coordinating anions, such as triflate or perchlorate (see Table S1 in the Supporting Information). ${ }^{[32]}$ These findings confirm that the dissimilarity is largely due to the presence of $\mathrm{Cl}^{-}$ and its coordination to Fe. In contrast, sulfate does not seem to hinder $\mathrm{Fe}$ in functioning as a redox mediator. Altogether, $\mathrm{FeCl}_{2}$ remained the best option in terms of catalyst activity and stability, as well as product selectivity, and was therefore used for further investigation.

Next, time profiles were constructed at $150^{\circ} \mathrm{C}$ under 20 bar $\mathrm{O}_{2}$ to develop a better understanding of the time-dependent changes in carbon yield and selectivity to GHB in the presence of $\mathrm{FeCl}_{2}$ (Figure 2). First, the more rapid increase in total carbon yield at short reaction times once again revealed that the Pt-based catalytic system exhibits a higher activity when $\mathrm{FeCl}_{2}$, instead of $\mathrm{CuCl}_{2}$, is applied as co-catalyst, suggesting that the oxidation of $\mathrm{Pt}^{\mathrm{II}}-\mathrm{R}$ to $\mathrm{Pt}^{\mathrm{IV}}-\mathrm{R}$ (Scheme 1 ) is likely the rate-determining step in the overall reaction. Moreover, a superior stability of the Pt catalyst was observed with $\mathrm{FeCl}_{2}$, as evidenced by the slower formation of metallic platinum on the bottom of the glass vial during reaction (Figure $2 \mathrm{a}^{*}{ }^{*}$ ). $\mathrm{FeCl}_{2}$ therefore appears to be more efficient than $\mathrm{CuCl}_{2}$ in reoxidizing $\mathrm{Pt}^{0}$ back to its catalytically active $\mathrm{Pt}^{\prime \prime}$ analogue, in a manner similar to that applied for the oxidation of $\mathrm{Pd}^{0}$ to $\mathrm{Pd}^{\prime \prime}$ in the Wacker process. ${ }^{[33]}$ More importantly, when using $\mathrm{FeCl}_{2}$, elevated selectivities were consistently observed for GHB over the full course of reaction (Figure $2 \mathrm{~b}$ ), presumably because of a reduced degree of non-selective side reactions. By combining these findings, a carbon yield of $37.5 \%$ was achieved with sufficiently high selectivity (71\%) and within $2 \mathrm{~h}$. Hence, $\mathrm{FeCl}_{2}$ is ideally suited to function as redox mediator between the Pt" $-\mathrm{R}$ complex and $\mathrm{O}_{2}$.
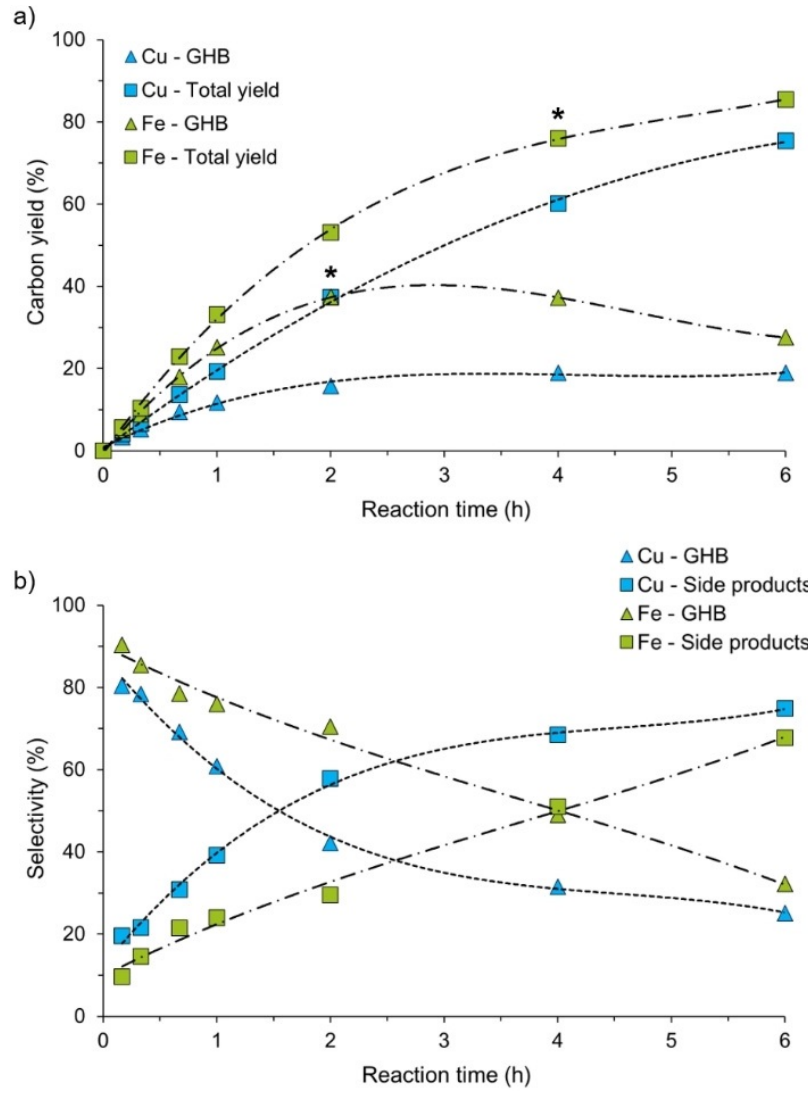

Figure 2. Time profiles of a) carbon yields and b) selectivities in the Pt-catalyzed hydroxylation of butyric acid with $\mathrm{O}_{2}$, in the presence of $\mathrm{CuCl}_{2}$ versus $\mathrm{FeCl}_{2}$ as co-catalyst. Conditions: butyric acid $(0.67 \mathrm{M}), \mathrm{K}_{2} \mathrm{PtCl}_{4}(1 \mathrm{~mol} \%)$, $\mathrm{H}_{2} \mathrm{SO}_{4}(0.33 \mathrm{M}), \mathrm{CuCl}_{2} \cdot 2 \mathrm{H}_{2} \mathrm{O} / \mathrm{FeCl}_{2} \cdot 4 \mathrm{H}_{2} \mathrm{O}(5 \mathrm{~mol} \%), \mathrm{H}_{2} \mathrm{O}(1.5 \mathrm{~mL}), 150^{\circ} \mathrm{C}, 20$ bar $\mathrm{O}_{2}$. ${ }^{*}$ Reaction time at which the formation of metallic platinum was first observed on the bottom of the glass vial after reaction.

\section{Experimental study of the catalyst activity and stability}

To better understand and optimize the catalytic system with $\mathrm{FeCl}_{2}$ as co-catalyst, several reaction variables were examined in detail. For this purpose, standard reactions were performed for $1 \mathrm{~h}$ and $6 \mathrm{~h}$, respectively, to ensure proper comparison of the acquired results in terms of catalyst activity and stability. 
Table 3. Experimental study of parameters influencing the catalyst activity in the Pt-catalyzed hydroxylation of butyric acid with $\mathrm{O}_{2}{ }^{\left[{ }^{[a]}\right.}$

\begin{tabular}{|c|c|c|c|c|c|c|c|c|c|c|c|c|}
\hline & \multirow[t]{2}{*}{ [Butyric acid] [M] } & \multirow{2}{*}[\mathrm{H}_{2}\mathrm{SO}_{4}]{$[\mathrm{M}]$} & \multirow[t]{2}{*}{$\mathrm{K}_{2} \mathrm{PtCl}_{4}[\mathrm{~mol} \%]$} & \multirow{2}{*}{$\mathrm{FeCl}_{2}[\mathrm{~mol} \%]$} & \multirow{2}{*}{$\mathrm{P}_{\mathrm{O} 2}[\mathrm{bar}]$} & \multirow[t]{2}{*}{$\mathrm{X}$ [\%] } & \multirow[t]{2}{*}{$\mathrm{S}$ [\%] } & \multicolumn{5}{|c|}{ Carbon yield $[\%]^{[b]}$} \\
\hline & & & & & & & & GHB & BHB & AHB & SA & $\mathrm{DP}^{[\mathrm{cl}}$ \\
\hline 1 & 0.67 & 0.33 & 1 & - & 20 & 3.2 & 44 & 1.4 & 0.3 & 0.2 & 0 & 1.3 \\
\hline 2 & 0.67 & 0.33 & 1 & 5 & 20 & 33.3 & 76 & 25.2 & 1.4 & 0.5 & 0.5 & 5.7 \\
\hline 3 & 0.67 & 0.33 & 1 & 5 & 5 & 5.6 & 66 & 3.7 & 0.3 & 0.9 & 0.1 & 0.6 \\
\hline 4 & 0.67 & 0.33 & 1 & 5 & 10 & 12.1 & 74 & 8.9 & 0.5 & 0.9 & 0.2 & 1.6 \\
\hline 5 & 0.67 & 0.33 & 1 & 5 & 30 & 14.7 & 73 & 10.7 & 0.6 & 0.8 & 0.2 & 2.4 \\
\hline 6 & 0.67 & 0.33 & 1 & 1 & 20 & 33.6 & 67 & 22.5 & 1.6 & 1.7 & 0.8 & 7.0 \\
\hline 7 & 0.67 & 0.33 & 1 & 10 & 20 & 13.3 & 68 & 9.0 & 0.5 & 1.1 & 0.1 & 2.6 \\
\hline 8 & 0.67 & 0.33 & 1 & 20 & 20 & 6.2 & 53 & 3.3 & 0.4 & 0.8 & 0.1 & 1.6 \\
\hline 9 & 0.67 & 0.33 & 0.5 & 2.5 & 20 & 6.9 & 72 & 5.0 & 0.3 & 0.2 & 0 & 1.4 \\
\hline 10 & 0.67 & 0.33 & 2 & 10 & 20 & 37.5 & 74 & 27.6 & 1.4 & 1.2 & 0.6 & 6.7 \\
\hline 11 & 0.67 & 0.33 & 5 & 25 & 20 & 43.2 & 72 & 31.2 & 2.6 & 1.2 & 1.2 & 7.0 \\
\hline 12 & 0.167 & 0.33 & 1 & 5 & 20 & 15.2 & 54 & 8.2 & 0.4 & 4.4 & 0.1 & 2.1 \\
\hline 13 & 0.33 & 0.33 & 1 & 5 & 20 & 14.5 & 64 & 9.3 & 0.4 & 2.2 & 0.1 & 2.5 \\
\hline 14 & 0.5 & 0.33 & 1 & 5 & 20 & 19.7 & 70 & 13.8 & 0.5 & 1.3 & 0.3 & 3.8 \\
\hline 15 & 0.67 & 0 & 1 & 5 & 20 & 21.2 & 74 & 15.6 & 1.0 & 0.8 & 0.4 & 3.4 \\
\hline 16 & 0.67 & 0.067 & 1 & 5 & 20 & 22.1 & 78 & 17.3 & 0.7 & 0.4 & 0.4 & 3.3 \\
\hline 17 & 0.67 & 0.2 & 1 & 5 & 20 & 29.8 & 76 & 22.7 & 0.9 & 0.6 & 0.5 & 5.1 \\
\hline $\begin{array}{l}{[\mathrm{a}]} \\
\text { hyd } \\
\mathrm{C} \text { in } \\
\text { acid }\end{array}$ & $\begin{array}{l}\text { ditions: butyric aci } \\
\text { kybutyric acid, BHB } \\
\text { e corresponding } \mathrm{p}\end{array}$ & $\begin{array}{l}0.167-0.67 \mathrm{M}) \\
\text { 3-hydroxybut } \\
\text { luct divided }\end{array}$ & $\begin{array}{l}{ }_{2} \mathrm{PtCl}_{4}(0.5-5 \mathrm{~mol} \\
\text { ic acid, } \mathrm{AHB}=\alpha-\mathrm{t} \\
\text { the total mmole }\end{array}$ & $\begin{array}{l}\mathrm{H}_{2} \mathrm{SO}_{4}(0-0.33 \\
\text { Iroxybutyric ac } \\
\mathrm{f} \mathrm{C} \mathrm{initially} \mathrm{sup}\end{array}$ & $\begin{array}{l}\mathrm{FeCl}_{2} \cdot 4 \mathrm{H}_{2} \\
\mathrm{SA}=\text { succ } \\
\text { ed in buty }\end{array}$ & $\begin{array}{l}1-25 n \\
\text { acid, } \\
\text { acid (4 }\end{array}$ & $\begin{array}{l}\text { o), } \mathrm{H}_{2} \mathrm{C} \\
=\text { degr } \\
\text { nol). [C }\end{array}$ & $\begin{array}{l}\text { tion } \\
\text { wer }\end{array}$ & adat & $\begin{array}{l}\text { Num } \\
\text { prod }\end{array}$ & & $\begin{array}{l}3=\gamma- \\
\text { les of } \\
\text { lactic }\end{array}$ \\
\hline
\end{tabular}

\section{Parameters influencing the catalyst activity}

A substantial raise in the conversion of butyric acid was observed when standard reactions were performed under increasing oxygen pressures, ranging from 5 to 20 bar (Table 3 , entries 2-4). This confirms that with $\mathrm{O}_{2}$ as terminal oxidant, the overall reaction rate is determined by the ease with which the $\mathrm{Pt}^{\mathrm{II}}-\mathrm{R}$ complex is oxidized to its $\mathrm{Pt} \mathrm{t}^{\mathrm{IV}}-\mathrm{R}$ analogue. Contrary to our expectations, further increasing the oxygen pressure to 30 bar resulted in a decrease in total activity (entry 5). Additionally, a similar negative relation was observed between the conversion and co-catalyst loading (entries 2, 7-8). Considering that this adverse impact at higher $\mathrm{FeCl}_{2}$ concentrations might be due to an elevated amount of chloride in solution (Figure S5), $\mathrm{FeCl}_{2}$ was replaced with $\mathrm{Fe}\left(\mathrm{ClO}_{4}\right)_{2}$ and reactions were performed under identical conditions. Although less pronounced, a reduction in total carbon yield was still observed when an increasing concentration of $\mathrm{Fe}\left(\mathrm{ClO}_{4}\right)_{2}$ was initially included in the substrate solution (Figure $\mathrm{S6}$ ). A reasonable explanation is that the undesired oxidation of $\left[\mathrm{Pt}^{\prime \prime} \mathrm{Cl}_{4}\right]^{2-}$ to $\left[\mathrm{Pt}^{\mathrm{IV}} \mathrm{Cl}_{6}\right]^{2-}$ is favored at high oxygen pressures or when too much co-catalyst is supplied and, in this way, diminishes the amount of active Pt catalyst during the reaction. ${ }^{[19,22]}$ On top of that, only a slight increase in conversion was observed when the catalyst loading was raised while keeping the catalyst/co-catalyst ratio constant (entries 2, 10-11). After reaction, the formation of metallic platinum at the bottom of the glass vial was observed. This deactivation within short reaction times suggests that at higher Pt concentrations i) disproportionation of $\mathrm{Pt}^{\prime \prime}$ to $\mathrm{Pt}^{0}$ and $\mathrm{Pt}^{\mathrm{IV}}$ [Eq. (1)] occurs more readily or ii) $\mathrm{Pt}^{\prime \prime}$ also partially functions as terminal oxidant in the oxidation of Pt" $-\mathrm{R}$ [Eq. (2)]:[3]
$2\left[\mathrm{Pt}^{\prime \prime} \mathrm{Cl}_{4}\right]^{2-} \rightarrow \mathrm{Pt}^{0}+\left[\mathrm{Pt}^{\prime \mathrm{V}} \mathrm{Cl}_{6}\right]^{2-}+2 \mathrm{Cl}^{-}$

$\left[\mathrm{Pt}^{\prime \prime} \mathrm{Cl} \mathrm{B}_{3}\right]^{2-}+\left[\mathrm{Pt}^{\prime \prime} \mathrm{Cl}_{4}\right]^{2-} \rightarrow\left[\mathrm{Pt}^{\prime \mathrm{V}} \mathrm{Cl}_{5} \mathrm{R}\right]^{2-}+\mathrm{Pt}^{0}+2 \mathrm{Cl}^{-}$

Both reactions decrease the amount of $\mathrm{Pt}$ " that is available for the $\mathrm{C}-\mathrm{H}$ activation of butyric acid, limiting the effect of higher catalyst loadings.

Furthermore, standard reactions were performed with different concentrations of butyric and sulfuric acid. As is evident from the data in Table 3, entries 2 and 12-14, a fourfold reduction of the substrate concentration corresponded to a strong decrease in conversion. This outcome can be rationalized in terms of the coordination equilibrium of butyric acid to Pt"; if the equilibrium is not very much to the right, dilution of butyric acid will diminish the fraction of $\mathrm{Pt}^{\prime \prime}$ that holds a butyrate ligand. As the solubility of $\mathrm{O}_{2}$ is often relatively low in aqueous solutions, ${ }^{[34]}$ this result can also be understood by considering that higher concentrations of an organic compound could increase the $\mathrm{O}_{2}$ solubility, and as a result, enhance the rate of the overall reaction. By analogy, the total carbon yield gradually declined upon lowering of the sulfuric acid concentration from $0.33 \mathrm{M}$ to $0 \mathrm{M}$ (entries 2, 15-17). A logical explanation is that the driving force for the reoxidation of $\mathrm{Fe}^{\text {II }}$ by $\mathrm{O}_{2}$ increases with decreasing $\mathrm{pH}$, since the oxidative half reaction of $\mathrm{Fe}^{\mathrm{III}} / \mathrm{Fe}^{\prime \prime}$ involves no protons, whereas a linear inverse correlation exists between the redox potential of $\mathrm{O}_{2} / \mathrm{H}_{2} \mathrm{O}$ and the $\mathrm{pH}$ following a Nernst-type equation. ${ }^{[27]}$ In addition, alternative inorganic and organic acids were evaluated under standard conditions (Figure S7). For instance, conversion was completely lost when $\mathrm{H}_{2} \mathrm{SO}_{4}$ was replaced with $\mathrm{HCl}$, which agrees with previous findings concerning (co-)catalyst deactivation at high chloride concentrations (Figure S5). In contrast, no apparent shift in total carbon yield was noted when similar reactions were performed 
in the presence of $\mathrm{CH}_{3} \mathrm{SO}_{3} \mathrm{H}, \mathrm{CF}_{3} \mathrm{SO}_{3} \mathrm{H}$ or $\mathrm{CF}_{3} \mathrm{COOH}$, whereas the use of solid acids, such as zeolite H-beta or amberlyst-15, led to a decrease in conversion.

\section{Improvement of the catalyst stability}

Although a highly active system was achieved by selecting a suitable redox mediator, catalyst deactivation by reduction to metallic platinum still occurred over time; in optimal conditions, the formation of a black precipitate was observed from a reaction time of $4 \mathrm{~h}$ on (Figure $2 \mathrm{a}$ ). For the purpose of prolonging the catalyst stability, the influence of adding suitable ligands was examined in the Pt-catalyzed hydroxylation of butyric acid. In particular, previous studies, for example, on the Periana-Catalytica system for methane oxidation with $\mathrm{SO}_{3},{ }^{[35,36]}$ have revealed the potential of bidentate $\mathrm{N}$-heteroaromatic ligands in stabilizing related $\mathrm{Pt}^{\prime \prime}$ complexes, based on the strong $\sigma$-donor and $\pi$-acceptor interactions of these ligands with electron rich low oxidation state metals. ${ }^{[3]}$

As shown in Table 4, no metallic platinum was detected in the reaction vial after $6 \mathrm{~h}$ when $1 \mathrm{~mol} \%$ of 2,2'-bipyridine was initially included in the substrate solution (entry 2). A similar improvement of the catalyst stability was, however, achieved with 1 mol\% of pyridine (entry 3), demonstrating that a monodentate ligand gives comparable stabilization as a bidentate, chelating ligand. Moreover, a negative impact on the activity was observed for both ligands, which proved to be more severe for 2,2'-bipyridine. Consequently, an inverse relation appears to exist between the affinity of the ligand for $\mathrm{Pt}^{\prime \prime}$ and the activity of the resulting catalyst complex. At the same time, this adverse relationship was alleviated when a strongly electron-withdrawing group, such as a F atom (entry 7), was incorporated in the 2-pyridyl position. By analogy to the work of Izawa and Stahl, ${ }^{[38]}$ these findings can be understood by con- sidering that a higher basicity of the pyridine nitrogen simultaneously results in a stronger $\sigma$-bond interaction and a lower electrophilicity of Pt". Since the electrophilic nature of Pt is essential for catalyst activity, ligands that are more basic tend to deactivate the catalytic system. Accordingly, the reduced basicity of 2-F-pyridine, compared to pyridine, allowed to stabilize the Pt catalyst without significantly altering the activity of the latter. In addition, a similar result was obtained with 2-OH-pyridine (entry 8). Although a $\mathrm{OH}$ group is intrinsically less electron-withdrawing than a $\mathrm{F}$ atom, the tautomerization of $2-\mathrm{OH}-$ pyridine to 2-pyridone in water reduces the basicity of this additive. ${ }^{[39-41]}$ Ultimately, it is also notable that with suitable ligands, such as 2-OH- or 2-F-pyridine, higher GHB selectivities are maintained up to high butyric acid conversions than in the absence of these ligands.

Strikingly, analogous results were achieved by introducing varying partial pressures of $\mathrm{N}_{2}(5-10 \mathrm{bar})$ in the gaseous atmosphere, while keeping the $\mathrm{O}_{2}$ partial pressure constant at 20 bar: no metallic platinum was visible after reaction of butyric acid for $6 \mathrm{~h}$. Additionally, too high $\mathrm{N}_{2}$ partial pressures resulted in a reduced catalyst activity, as evidenced by the significant drop in conversion (Figure 3), which indicated that $\mathrm{N}_{2}$ in some way influences the catalytic system. In fact, this specific role of $\mathrm{N}_{2}$ was confirmed by the observation that no stabilizing effect was found when identical reactions were performed with different partial pressures of He (Table S2, entries 1, 5-6). Furthermore, replacing $\mathrm{FeCl}_{2}$ with $\mathrm{CuCl}_{2}$ also led to a complete loss of the beneficial effects (Table S2, entries 7-10), suggesting that the activity of $\mathrm{Fe}$, and not $\mathrm{Pt}$, is positively modified by $\mathrm{N}_{2}$. As the role of $\mathrm{Fe}$ is to reoxidize $\mathrm{Pt}^{0}$ to $\mathrm{Pt}^{\prime \prime}$, the hydroxylation of butyric acid was studied using $\mathrm{FeCl}_{2}$, but with initial addition of $\mathrm{Pt}^{0}$, instead of $\mathrm{Pt}^{\mathrm{I}}$, to the reaction mixture and with variation of the atmospheric composition. After $6 \mathrm{~h}$, much higher butyric acid conversions were observed when the gaseous atmos-

\begin{tabular}{|c|c|c|c|c|c|c|c|c|c|}
\hline & \multirow[t]{2}{*}{ Ligand } & \multirow[t]{2}{*}{ Metallic platinum ${ }^{[b]}$} & \multirow[t]{2}{*}{$\mathrm{X}[\%]$} & \multirow[t]{2}{*}{$\mathrm{S}[\%]$} & \multicolumn{5}{|c|}{ Carbon yield $[\%]^{[c]}$} \\
\hline & & & & & GHB & $\mathrm{BHB}$ & AHB & SA & $D P^{[d]}$ \\
\hline 1 & - & & 85.5 & 32 & 27.6 & 1.4 & 0.8 & 1.9 & 53.8 \\
\hline 2 & 2,2'-bipyridine & & 9.4 & 3 & 0.3 & 0.2 & 0 & 0 & 8.9 \\
\hline 3 & pyridine & & 32.4 & 50 & 16.3 & 0.7 & 1.0 & 0.3 & 14.1 \\
\hline 4 & 2-phenylpyridine & & 7.4 & 26 & 1.9 & 0.2 & 0 & 0 & 5.3 \\
\hline 5 & 2-chloropyridine & & 29.9 & 57 & 16.9 & 2.2 & 2.0 & 0 & 8.8 \\
\hline 6 & 2-trifluoromethylpyridine & & 49.8 & 49 & 24.5 & 1.3 & 2.0 & 0.8 & 21.2 \\
\hline 7 & 2-fluoropyridine & & 82.8 & 40 & 33.0 & 1.4 & 1.1 & 2.1 & 45.2 \\
\hline 8 & 2-hydroxypyridine & & 77.3 & 45 & 34.6 & 1.5 & 0.8 & 1.5 & 38.9 \\
\hline
\end{tabular}

[a] Conditions: butyric acid $(0.67 \mathrm{M}), \mathrm{K}_{2} \mathrm{PtCl}_{4}(1 \mathrm{~mol} \%), \mathrm{H}_{2} \mathrm{SO}_{4}(0.33 \mathrm{M}), \mathrm{FeCl}_{2} \cdot 4 \mathrm{H}_{2} \mathrm{O}(5 \mathrm{~mol} \%)$, ligand $(1 \mathrm{~mol} \%), \mathrm{H}_{2} \mathrm{O}(1.5 \mathrm{~mL}), 6 \mathrm{~h}, 150{ }^{\circ} \mathrm{C}, 20 \mathrm{bar} \mathrm{O}_{2} . \mathrm{GHB}=\gamma-$ hydroxybutyric acid, $\mathrm{BHB}=\beta$-hydroxybutyric acid, $\mathrm{AHB}=\alpha$-hydroxybutyric acid, $\mathrm{SA}=$ succinic acid, $\mathrm{DP}=$ degradation products. [b] Visual observation of metallic platinum at the bottom of the glass vial after reaction? $\Theta=$ Yes, $(=$ No. [c] Number of mmoles of $C$ in the corresponding product divided by the total mmoles of $C$ initially supplied in butyric acid $(4 \mathrm{mmol})$. [d] Lower degradation products include lactic acid, acetone, acetic acid, glycolic acid, acetaldehyde, formic acid, methanol and gaseous compounds. 


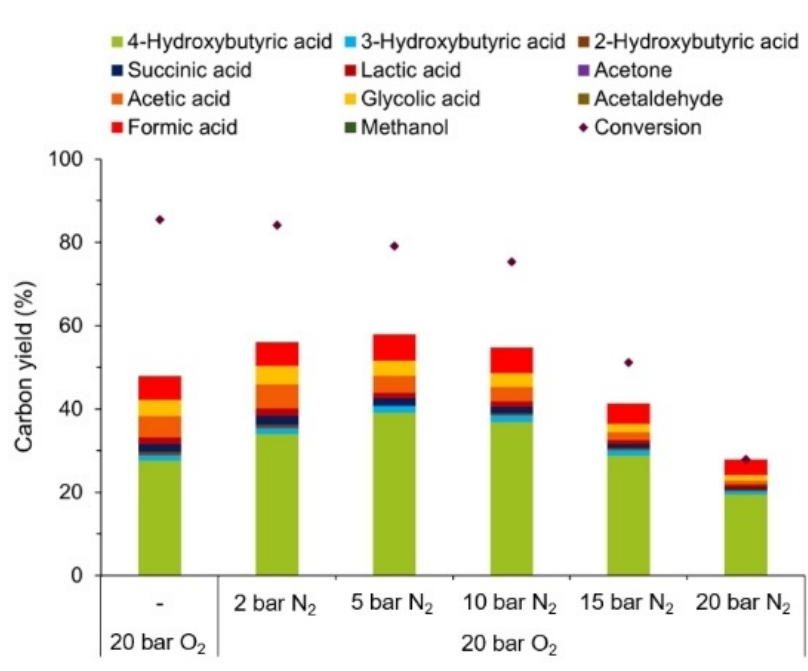

Figure 3. Pt-catalyzed hydroxylation of butyric acid under 20 bar $\mathrm{O}_{2}$ and varying partial pressures of $\mathrm{N}_{2}$. Conditions: butyric acid $(0.67 \mathrm{M}), \mathrm{K}_{2} \mathrm{PtCl}_{4}$ (1 mol\%), $\mathrm{H}_{2} \mathrm{SO}_{4}(0.33 \mathrm{M}), \mathrm{FeCl}_{2} \cdot 4 \mathrm{H}_{2} \mathrm{O}(5 \mathrm{~mol} \%), \mathrm{H}_{2} \mathrm{O}(1.5 \mathrm{~mL}), 6 \mathrm{~h}, 150^{\circ} \mathrm{C}, 20$ bar $\mathrm{O}_{2} / 2-20$ bar $\mathrm{N}_{2}$.

phere was complemented with 5 bar of $\mathrm{N}_{2}$ (Figure 4), giving evidence that the specific combination of an Fe salt and $\mathrm{N}_{2}$ is more effective in activating $\mathrm{Pt}^{0}$. Since $\mathrm{N}_{2}$ is considered to be rather inert, the presence of more reactive nitrogen oxides $\left(\mathrm{NO}_{\mathrm{x}}\right)$ was investigated. Quantitative infrared spectroscopy of the vapor phase was therefore conducted; the IR data clearly revealed characteristic bands corresponding to the $\mathrm{N}-\mathrm{O}$ stretch vibration of nitrogen monoxide (Figure S8). In summary, a reasonable explanation for the stabilizing effect of $\mathrm{N}_{2}$ is that minor amounts of NO, or other $\mathrm{N}$-oxides, are formed in situ under the oxidative conditions and as such, or upon activation by $\mathrm{Fe}_{1}^{[42]}$ facilitate the reoxidation of $\mathrm{Pt}^{0}$ during the reaction. Furthermore, higher concentrations of these $\mathrm{N}$-oxides are likely to be formed at elevated partial pressures of $\mathrm{N}_{2}$, which, by analogy to the reoxidation of $\mathrm{Pt}^{0}$, could favor the undesired ox-

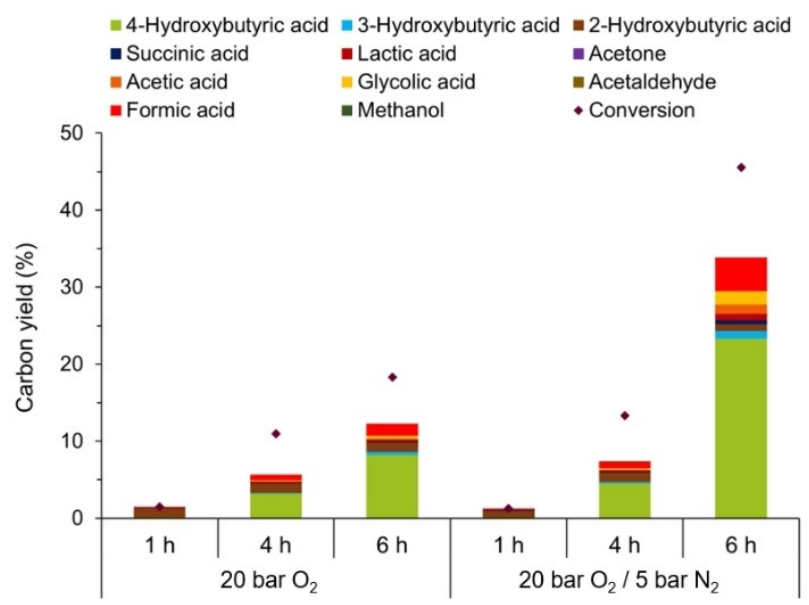

Figure 4. Influence of introducing $\mathrm{N}_{2}$ in the gaseous atmosphere on the rate of $\mathrm{Pt}^{0}$ reoxidation. Conditions: butyric acid $(0.67 \mathrm{M}), \mathrm{Pt}^{0}(1 \mathrm{~mol} \%), \mathrm{H}_{2} \mathrm{SO}_{4}$ (0.33 M), $\mathrm{FeCl}_{2} \cdot 4 \mathrm{H}_{2} \mathrm{O}(5 \mathrm{~mol} \%), \mathrm{H}_{2} \mathrm{O}(1.5 \mathrm{~mL}), 1-6 \mathrm{~h}, 150^{\circ} \mathrm{C}, 20$ bar $\mathrm{O}_{2} / 5$ bar $\mathrm{N}_{2}$ idation of $\left[\mathrm{Pt}^{\mathrm{II}} \mathrm{Cl}_{4}\right]^{2-}$ to $\left[\mathrm{Pt}^{\mathrm{IV}} \mathrm{Cl}_{6}\right]^{2-}$, thereby reducing the amount of active catalyst in solution and limiting the conversion.

Even though the formation of metallic platinum has generally been accepted as a measure of $\mathrm{Pt}^{\prime \prime}$ deactivation in Shilov chemistry, supporting evidence for the enhanced catalyst stability was obtained by determining the Pt" activity after including a second batch of substrate. For this, time-dependent changes in the yield of GHB were evaluated after adding $1 \mathrm{mmol}$ of butyric acid to substrate mixtures already subjected to a reaction for $6 \mathrm{~h}$ with and without either of the two nitrogen-containing additives. As indicated in Figure S9, a substantial reduction in yield occurred after $10 \mathrm{~h}$ under standard reaction conditions. Conversely, a continuous formation of GHB up to $12 \mathrm{~h}$ was observed i) in the presence of 2-F-pyridine ( $1 \mathrm{~mol} \%$ ) as well as ii) after introducing $\mathrm{N}_{2}$ (5 bar) in the gaseous atmosphere. Accordingly, this prolonged catalyst activity under the optimized conditions could be attributed to a superior stability of the Pt catalyst.

\section{Selectivity enhancing strategies}

Thus far, high selectivities for GHB ( $\geq 70 \%)$ were only maintained at relatively low conversion $(\leq 50 \%$, Figure 2$)$. As previously mentioned, multiple byproducts, including succinic acid, as well as lower degradation and gaseous compounds, were identified after conducting a qualitative 1D and 2D NMR analysis of the product mixture, in combination with infrared spectroscopy of the vapor phase. Developing a more comprehensive understanding of how these undesirable products are formed during reaction is therefore essential to enhance the preferential formation of GHB at elevated conversions. For instance, the gradually decreasing carbon yield of GHB at longer reaction times (Figure $2 \mathrm{a}$ ) points to the occurrence of consecutive overoxidation reactions. To study this stability issue and to evaluate the catalytic activity of certain compounds towards these non-selective side reactions, GHB was first synthesized according to the procedure described by Ferris and Went; ${ }_{i}^{[43]}$ the purity of the resulting sample was determined by ${ }^{1} \mathrm{H}$ NMR (Figure S10). Next, $1 \mathrm{mmol}$ of GHB was added to distinct solutions containing a) no catalyst or co-catalyst, b) $\mathrm{FeCl}_{2}$, c) $\mathrm{Pt}^{0}$, d) $\mathrm{K}_{2} \mathrm{PtCl}_{4}$ and e) $\mathrm{K}_{2} \mathrm{PtCl}_{4}$ as well as $\mathrm{FeCl}_{2}$, after which a kinetic profile was recorded at short reaction times and under standard reaction conditions $\left(0.33 \mathrm{M} \mathrm{H}_{2} \mathrm{SO}_{4}, 150^{\circ} \mathrm{C}, 20\right.$ bar $\left.\mathrm{O}_{2}\right)$ for each of the resulting mixtures.

As shown in Figure $5 \mathrm{a}, \mathrm{GHB}$ remained fully stable in the absence of any (co-)catalyst, as well as upon the addition of $\mathrm{FeCl}_{2}$ to the substrate solution. Hence, the possibility of a radicalmediated initiation seems excluded. On the other hand, overoxidation of the remote hydroxyl group took place to a considerable extent when $\mathrm{K}_{2} \mathrm{PtCl}_{4}$ was included, as demonstrated by the predominant formation of succinic acid during the reaction (Figure $5 \mathrm{~b}$ ). Although this side reaction appeared to correspond to the well-known oxidative transformation of alcohols on metallic platinum, ${ }^{[44]}$ no degradation of GHB occurred over time in the presence of $\mathrm{Pt}^{0}$. Given these observations, the Ptmediated degradation can be rationalized by assuming that GHB remains coordinated to the Pt" center through its hydrox- 
a)

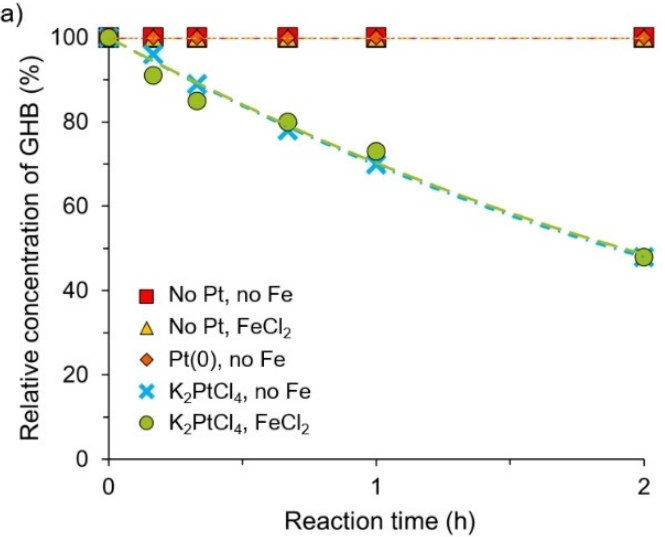

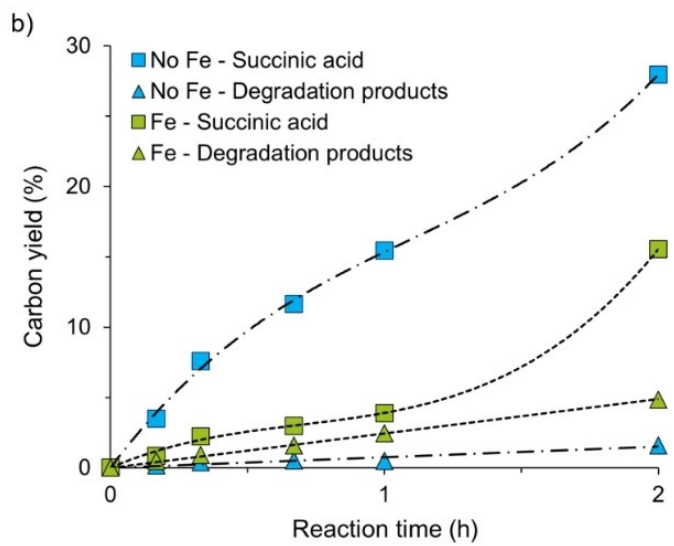

Figure 5. Stability of $\gamma$-hydroxybutyric acid (GHB) in the Pt-catalyzed hydroxylation of butyric acid with $\mathrm{O}_{2}$, illustrated by the time-dependent changes in a) relative concentration of GHB and b) carbon yields of the side products formed. Conditions: $\gamma$-hydroxybutyric acid $(0.67 \mathrm{M}), \mathrm{K}_{2} \mathrm{PtCl}_{4}(0-1 \mathrm{~mol} \%), \mathrm{Pt}^{0}(0-1 \mathrm{~mol} \%)$, $\mathrm{H}_{2} \mathrm{SO}_{4}(0.33 \mathrm{M}), \mathrm{FeCl}_{2} \cdot 4 \mathrm{H}_{2} \mathrm{O}(0-5 \mathrm{~mol} \%), \mathrm{H}_{2} \mathrm{O}(1.5 \mathrm{~mL}), 0-2 \mathrm{~h}, 150^{\circ} \mathrm{C}, 20$ bar $\mathrm{O}_{2}$

yl group, rendering the $\alpha-\mathrm{C}-\mathrm{H}$ bonds susceptible to further oxidation. Moreover, adding $\mathrm{FeCl}_{2}$ to the catalyst-containing solution gave rise to a significantly altered product distribution, whereas no additional decrease in the relative concentration of GHB occurred. More specifically, a reduced amount of succinic acid was invariably detected, together with elevated levels of the lower degradation products acetic acid and glycolic acid. Additionally, comparison of the vapor phase composition by quantitative infrared spectroscopy revealed an increased formation of $\mathrm{CO}_{2}, \mathrm{CO}, \mathrm{CH}_{4}$ and acetaldehyde. This particular change in the product distribution suggests that $\mathrm{Fe}^{\mathrm{II} /} / \mathrm{Fe}^{\prime \prime}$ accelerates the decarboxylation of succinaldehydic acid and succinic acid through one-electron oxidations, along with the oxidative C-C cleavage of both compounds. ${ }^{[45]}$ In short, $\mathrm{K}_{2} \mathrm{PtCl}_{4}$ and $\mathrm{FeCl}_{2}$ not only catalyze the regioselective $\mathrm{C}-\mathrm{H}$ hydroxylation of butyric acid to GHB, but also appear to facilitate consecutive reactions of the latter, leading to undesirable selectivities at high conversions.

To stop the oxidation process at the level of GHB, by preventing further oxidation of the remote hydroxyl moiety, standard reactions were performed with varying amounts of boric acid $\left(\mathrm{H}_{3} \mathrm{BO}_{3}\right)$. In fact, $\mathrm{H}_{3} \mathrm{BO}_{3}$ has been applied for many years in hydrocarbon oxidation processes, for example, the autoxidation of linear saturated alkanes to secondary alcohols, with the purpose of controlling the chemoselectivity. ${ }^{[45-47]}$ It is believed that esterification of $\mathrm{H}_{3} \mathrm{BO}_{3}$ to the corresponding borate ester is able to protect the alcohol product from further oxidation; the electron-withdrawing nature of the boron atom lowers the electron density of the neighboring $\mathrm{C}-\mathrm{H}$ bonds, causing $\mathrm{H}$-abstraction by radicals to be unfavorable. ${ }^{[47]}$ However, this reduced electron richness of the $\alpha-\mathrm{C}-\mathrm{H}$ bonds might presumably also lower their tendency to coordinate to the electrophilic Pt catalyst and, therefore, reduce their reactivity towards overoxidation. Consequently, by including 1 equivalent of $\mathrm{H}_{3} \mathrm{BO}_{3}$, a selectivity of $70 \%$ could be maintained at much higher conversion, yielding $47 \%$ of GHB within $6 \mathrm{~h}$ and a TON of 67 (Figure 6). At the same time, combining this protective effect with the addition of stabilizing agents turned out unsuccessful, since esterification was negatively affected in the presence of

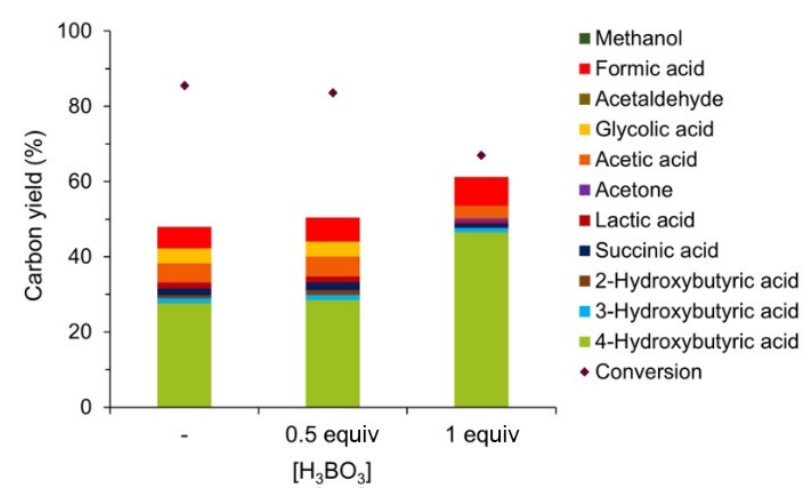

Figure 6. Pt-catalyzed hydroxylation of butyric acid with $\mathrm{O}_{2}$ and varying amounts of boric acid $\left(\mathrm{H}_{3} \mathrm{BO}_{3}\right)$. Conditions: butyric acid $(0.67 \mathrm{M}), \mathrm{K}_{2} \mathrm{PtCl}_{4}$ (1 mol \%), $\mathrm{H}_{2} \mathrm{SO}_{4}(0.33 \mathrm{M}), \mathrm{FeCl}_{2} \cdot 4 \mathrm{H}_{2} \mathrm{O}$ (5 mol\%), $\mathrm{H}_{3} \mathrm{BO}_{3}(0-0.67 \mathrm{M}), \mathrm{H}_{2} \mathrm{O}$ $(1.5 \mathrm{~mL}), 6 \mathrm{~h}, 150^{\circ} \mathrm{C}, 20$ bar $\mathrm{O}_{2}$.

pyridine derivatives, such as $2-\mathrm{F}$ - or $2-\mathrm{OH}$-pyridine (see the Supporting Information, Table S3). Nonetheless, limiting the interaction between the desired product and $\mathrm{Pt}$ " proved to be an appropriate strategy to avoid non-selective consecutive reactions.

As was already evident from Figure $2 b$, non-selective overoxidation reactions were considerably more prominent when $\mathrm{CuCl}_{2}$, instead of $\mathrm{FeCl}_{2}$, was applied as co-catalyst, which translated into lower selectivities over the full course of reaction. Moreover, quantitative infrared spectroscopy revealed a larger amount of gaseous products for the $\mathrm{Cu}$-mediated reaction. To evaluate the applicability of the above-mentioned approach, standard reactions with $\mathrm{CuCl}_{2}$ were also performed in the presence of $0.5-1$ equivalents of $\mathrm{H}_{3} \mathrm{BO}_{3}$. However, only a negligible increase in selectivity of GHB was observed (Figure S11). On the contrary, the selectivity to GHB for the Cu co-catalyzed reaction surprisingly improved when sulfuric acid was fully omitted from the substrate mixture (Figure S12). Despite the slight decrease in catalyst activity, a selectivity of $>80 \%$ was retained within the first $2 \mathrm{~h}$ (Figure 7). Although $\mathrm{FeCl}_{2}$ is still the preferred co-catalyst in terms of catalyst activity and stability, this 

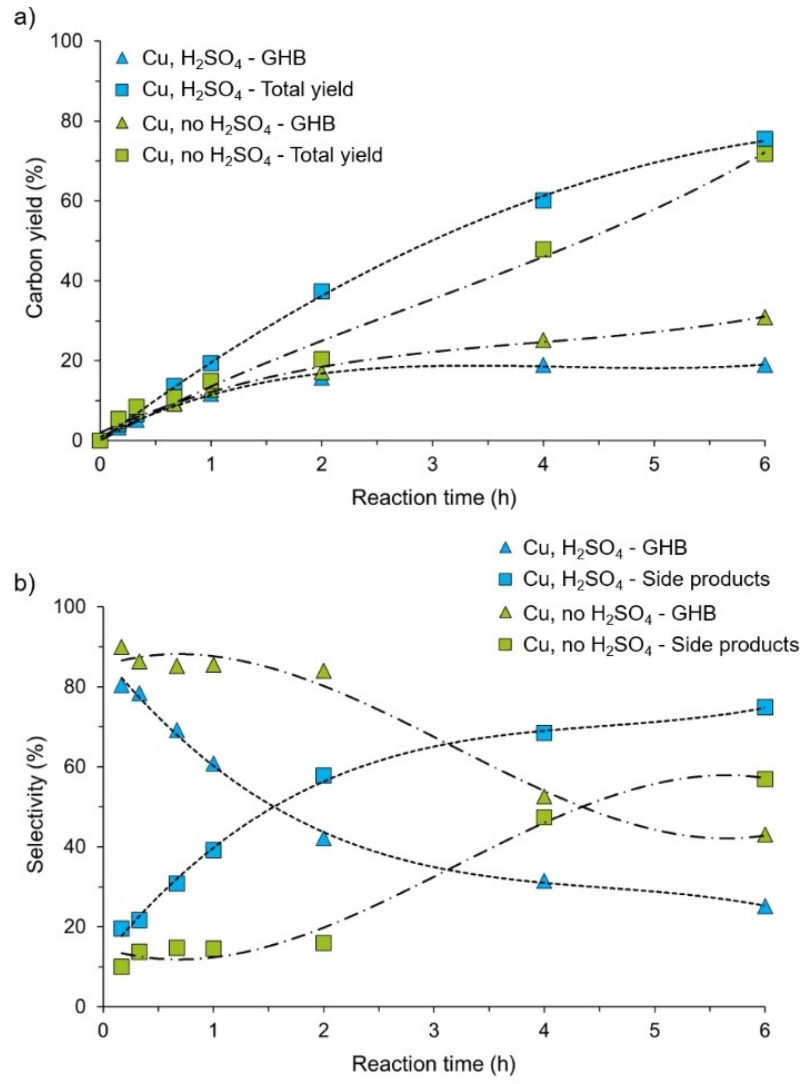

Figure 7. Time profiles of a) carbon yields and b) selectivities in the Pt-catalyzed hydroxylation of butyric acid with $\mathrm{O}_{2}$ and varying concentrations of sulfuric acid, in the presence of $\mathrm{CuCl}_{2}$ as the co-catalyst. Conditions: butyric acid $(0.67 \mathrm{M}), \mathrm{K}_{2} \mathrm{PtCl}_{4}(1 \mathrm{~mol} \%), \mathrm{H}_{2} \mathrm{SO}_{4}(0-0.33 \mathrm{M}), \mathrm{CuCl}_{2} \cdot 2 \mathrm{H}_{2} \mathrm{O}(5 \mathrm{~mol} \%), \mathrm{H}_{2} \mathrm{O}$ $(1.5 \mathrm{~mL}), 150^{\circ} \mathrm{C}, 20$ bar $\mathrm{O}_{2}$.

observation is quite remarkable and is most likely related to the speciation of $\mathrm{Cu}^{\text {Il }}$ in solution. First, one must note that $\mathrm{CuCl}_{2}$ is expected to partially dissociate to free $\mathrm{Cu}^{\prime \prime}$, as a moderately low equilibrium constant has been reported for the interaction of $\mathrm{Cu}^{\text {II }}$ with one or more $\mathrm{Cl}^{-}$ions. ${ }^{[48]}$ Conversely, $\mathrm{Cu}^{\text {II }}$ has a high tendency to associate with $\mathrm{SO}_{4}{ }^{2-},{ }^{[49]}$ which indicates that $\mathrm{CuCl}_{2}$ is partially transformed into $\mathrm{CuSO}_{4}$ when $\mathrm{H}_{2} \mathrm{SO}_{4}$ is present. Moreover, stability tests with varying $\mathrm{H}_{2} \mathrm{SO}_{4}$ concentrations revealed a notable change in the side product distribution; an elevated concentration of the degradation product acetic acid was observed in $\mathrm{H}_{2} \mathrm{SO}_{4}$-free conditions. In addition, Imamura et al. ${ }^{[50]}$ reported that $\mathrm{CuSO}_{4}$ is more active in the oxidative decomposition of acetic acid than $\mathrm{CuCl}_{2}$, due to its superior stability in solution at high temperatures. Analogously, a more advanced degree of GHB degradation was observed upon replacing $\mathrm{CuCl}_{2}$ with $\mathrm{CuSO}_{4}$ (Figure S13), which led us to believe that in situ formed $\mathrm{CuSO}_{4}$ is responsible for the higher degree of overoxidation. Altogether, these findings provide a possible explanation for the unusual relation between the sulfuric acid concentration and selectivity for GHB in reactions that use $\mathrm{Cu}$ as the co-catalyst.

\section{Conclusions}

By implementing $\mathrm{FeCl}_{2}$ as appropriate co-catalyst, we have successfully demonstrated the potential of using $\mathrm{O}_{2}$ as terminal oxidant in realizing a practical Shilov-chemistry-inspired Ptbased system for the selective terminal hydroxylation of cheap and abundant aliphatic compounds. As opposed to current state-of-the-art systems, a notable increase in the catalytic activity was achieved for the conversion of butyric acid, together with the selective formation of GHB. Accordingly, the intrinsic activity of the proposed system was studied in detail by carefully exploring the different reaction parameters. Moreover, adding catalytic amounts of ortho-functionalized pyridine derivatives proved to be an effective way to improve the catalyst stability. A similar outcome was achieved by introducing $\mathrm{N}_{2}$ in the gaseous atmosphere, which was explained in terms of the role played by in situ formed $\mathrm{N}$-oxides. Finally, insights into the potential overoxidation pathways of GHB revealed the need for suitable protecting agents, such as boric acid, which allowed to attain elevated selectivities $(70 \%)$ at much higher conversion (>60\%).

\section{Experimental Section}

\section{Catalytic reaction}

In a typical reaction, a glass reaction vial $(5.5 \mathrm{~mL})$ was loaded with the substrate $(0.67 \mathrm{M})$, a noble metal catalyst $(1 \mathrm{~mol} \%)$, a co-catalyst $(5 \mathrm{~mol} \%)$, an acid $(0.33 \mathrm{M})$, deionized water $(1.5 \mathrm{~mL})$ and a magnetic stirring bar. After partially closing the vial with a teflon stopper, it was positioned into a stainless steel reactor $(11 \mathrm{~mL})$. The reactor was sealed, after which its atmosphere was purged for $5 \mathrm{~s}$ with pure $\mathrm{O}_{2}$ and pressurized with 20 bar $\mathrm{O}_{2}$. Next, while stirring at $500 \mathrm{rpm}$, the reaction was initiated by heating the reactor to $150^{\circ} \mathrm{C}$ and time recording was started when this temperature was reached. After $6 \mathrm{~h}$, heating was discontinued and the reaction was quenched by cooling of the reactor on ice. Ultimately, the residual solution was separated and analyzed as such by proton nuclear magnetic resonance ( ${ }^{1} \mathrm{H}$ NMR) spectroscopy. Due to difficulties related to the paramagnetism of iron (Fe) in NMR measurements, Fecontaining mixtures were first basified by adding $1.5 \mathrm{~mL}$ of a concentrated solution of $\mathrm{NaOH}(2 \mathrm{M})$. This change in $\mathrm{pH}$ caused a complete precipitation of the iron species present in solution. Afterwards, the precipitate was removed by centrifugation $(10 \mathrm{~min}$, $3200 \mathrm{rpm}$ ) and the supernatant was analyzed in a similar fashion.

\section{Product analysis and identification}

To quantify the product yields, reaction mixtures were analyzed by ${ }^{1} \mathrm{H}$ NMR spectroscopy. Samples were first prepared by transferring $100 \mu \mathrm{L}$ of the product solution to $500 \mu \mathrm{L}$ of $\mathrm{D}_{2} \mathrm{O}$, containing an external standard (benzyl alcohol, $0.133 \mathrm{M}$ ), after which corresponding ${ }^{1} \mathrm{H}$ NMR spectra were recorded on a Bruker Ascend $400 \mathrm{MHz}$ spectrometer equipped with a BBO $5 \mathrm{~mm}$ atma probe and a sample case. During measurements, the broad water signal was suppressed by applying a zgpr pulse program, p1 $9.75 \mu \mathrm{s} ; \mathrm{ns} 32$; d1 $25 \mathrm{~s}$; aq $2.55 \mathrm{~s}$; plw1 $15 \mathrm{~W}$; plw9 $5.7 \times 10^{-5} \mathrm{~W}$; o1P, on the resonance signal of water, determined and selected automatically. In addition, ${ }^{13} \mathrm{C}$ NMR and two distinct methods of 2D NMR were combined to elucidate the identity of all products observed in the ${ }^{1} \mathrm{H}$ NMR spectrum of a standard reaction mixture. ${ }^{13} \mathrm{C}$ NMR was car- 
ried out according to the following pulse program: $17.65 \mu \mathrm{s}$, ns 1024, d1 2 s, plw1 $120 \mathrm{~W}$, plw2 $15 \mathrm{~W}$, plw12 $0.19 \mathrm{~W}$, plw13 $0.09 \mathrm{~W}$; ${ }^{1} \mathrm{H}-{ }^{13} \mathrm{C}$ NMR over 1 bond (HSQC) according to the following pulse program: p1 $9.75 \mu \mathrm{s}, \mathrm{p} 219.50 \mu \mathrm{s}, \mathrm{p} 37.50 \mu \mathrm{s}, \mathrm{p} 415 \mu \mathrm{s}$, ns 128, d1 $1.41 \mathrm{~s}$, plw1 $15 \mathrm{~W}$, plw2 $120 \mathrm{~W}$, plw12 $1.05 \mathrm{~W}$; and ${ }^{1} \mathrm{H}-{ }^{13} \mathrm{C}$ NMR over 2 or 3 bonds (HMBC) according to the following pulse program: p1 $9.75 \mu \mathrm{s}, \mathrm{p} 219.50 \mu \mathrm{s}, \mathrm{p} 37.50 \mu \mathrm{s}, \mathrm{ns} 40, \mathrm{~d} 11.41 \mathrm{~s}$, plw1 $15 \mathrm{~W}$, plw2 $120 \mathrm{~W}$. Furthermore, to account for the non-selective $\mathrm{C}-\mathrm{C}$ cleavage of primary reaction products towards lower degradation byproducts, yields were calculated as follows: the amount of mmoles for each compound was determined by comparing the normalized peak area with the one obtained for benzyl alcohol, from which a carbon yield was obtained by dividing the number of mmoles of $\mathrm{C}$ in the corresponding product by the total mmoles of $C$ initially supplied in the substrate $(4 \mathrm{mmol})$. Finally, quantitative Fourier transform infrared (FTIR) spectroscopy was conducted, using a Gasmet DX4000 FTIR gas analyzer, to evaluate the presence of gaseous products in the vapor phase. Prior to each measurement, part of the vapor phase was transferred from the reactor into a plastic syringe $(5 \mathrm{~mL})$ and injected as such into a $\mathrm{N}_{2}$ stream $\left(160 \mathrm{~mL} \mathrm{~min}^{-1}\right)$. Next, volume concentrations of the various compounds were measured at the detector level and were processed using the Calcmet Standard software version 12.161.

\section{Acknowledgements}

M.J. thanks the Fonds Wetenschappelijk Onderzoek (FWO), the Agency for Innovation by Science and Technology (IWT) and the Industrial Research Fund (IOF) of KU Leuven for funding. D.E.D.V. acknowledges the IWT and FWO for research project funding, the Flemish government for long-term structural funding through Methusalem, and Belspo (IAP-PAI 7/05) for financial support. The authors also thank Karel Deurinckx for his assistance throughout the NMR measurements and Sabina Accardo for her support during FTIR analysis of the vapor phase.

\section{Conflict of interest}

The authors declare no conflict of interest.

Keywords: $\mathrm{C}-\mathrm{H}$ activation - hydroxylation - molecular oxygen $\cdot$ platinum $\cdot$ primary $\mathrm{C}-\mathrm{H}$ bonds

[1] S. S. Stahl, J. A. Labinger, J. E. Bercaw, Angew. Chem. Int. Ed. 1998, 37, 2180-2192; Angew. Chem. 1998, 110, 2298-2311.

[2] a) J. F. Hartwig, M. A. Larsen, ACS Cent. Sci. 2016, 2, 281-292; b) V. Dantignana, M. Milan, O. Cussó, A. Company, M. Bietti, M. Costas, ACS Cent Sci. 2017, 3, 1350-1358.

[3] J. A. Labinger in Alkane $\mathrm{C}-\mathrm{H}$ activation by single-site metal catalysis, Vol. 39, (Ed.: P. J. Pérez), Springer, Dordrecht, 2012, pp. 17-72.

[4] J. A. Labinger, J. E. Bercaw, Nature 2002, 417, 507-514.

[5] K. Noweck, W. Grafahrend in Ullmann's encyclopedia of industrial chemistry, Vol. 14, Wiley-VCH, Weinheim, 2006, pp. 117-142.

[6] X. Tang, X. Jia, Z. Huang, Chem. Sci. 2018, 9, 288-299.

[7] A. E. Shilov, G. B. Shul'pin, Chem. Rev. 1997, 97, 2879-2932.

[8] F. Roudesly, J. Oble, G. Poli, J. Mol. Catal. A 2017, 426, 275-296.

[9] A. Sen, Acc. Chem. Res. 1998, 31, 550-557.

[10] E. G. Chepaikin, Russ. Chem. Rev. 2011, 80, 363-396.

[11] J. L. Garnett, R. J. Hodges, J. Am. Chem. Soc. 1967, 89, 4546-4547.

[12] a) N. F. Goldshleger, M. B. Tyabin, A. E. Shilov, A. A. Shteinman, Zh. Fiz. Khim. 1969, 43, 2174; b) N. F. Goldshleger, V. V. Eskova, A. E. Shilov, A. A. Shteinman, Zh. Fiz. Khim. 1972, 46, $1353-1354$.
[13] a) A. A. Shteinman, J. Organomet. Chem. 2015, 793, 34-40; b) A. A. Shteinman, J. Mol. Catal. A: Chem. 2017, 426, 305-315.

[14] G. A. Luinstra, L. Wang, S. S. Stahl, J. A. Labinger, J. E. Bercaw, J. Organomet. Chem. 1995, 504, 75-91.

[15] a) L.-C. Kao, A. Sen, J. Chem. Soc. Chem. Commun. 1991, 1242-1243; b) A. Sen, M. Lin, L.-C. Kao, A. C. Hutson, J. Am. Chem. Soc. 1992, 114, 6385-6392; c) N. Basickes, A. Sen, Polyhedron 1995, 14, 197-202; d) A. C. Hutson, M. Lin, N. Basickes, A. Sen, J. Organomet. Chem. 1995, 504, 69-74.

[16] M. Lee, M. S. Sanford, J. Am. Chem. Soc. 2015, 137, 12796-12799.

[17] B. D. Dangel, J. A. Johnson, D. Sames, J. Am. Chem. Soc. 2001, 123, 8149-8150.

[18] E. Roduner, W. Kaim, B. Sarkar, V. B. Urlacher, J. Pleiss, R. Gläser, W.-D. Einicke, G. A. Sprenger, U. Beifuß, E. Klemm, C. Liebner, H. Hieronymus, S.F. Hsu, B. Plietker, S. Laschat, ChemCatChem 2013, 5, 82-112.

[19] J. A. Labinger, Chem. Rev. 2017, 117, 8483-8496.

[20] N. F. Goldshleger, V. V. Lavrushko, A. P. Khrushch, A. A. Shteinman, IzV. Akad. Nauk SSSR Ser. Khim. 1976, 2174-2178.

[21] M. Lin, C. Shen, E. A. Garcia-Zayas, A. Sen, J. Am. Chem. Soc. 2001, 123, $1000-1001$.

[22] D. R. Weinberg, J. A. Labinger, J. E. Bercaw, Organometallics 2007, 26, $167-172$.

[23] Y. V. Geletii, A. E. Shilov, Kinet. Katal. 1983, 24, 486-489.

[24] M. S. Freund, J. A. Labinger, N. S. Lewis, J. E. Bercaw, J. Mol. Catal. 1994, 87, L11-L15.

[25] I. Bar-Nahum, A. M. Khenkin, R. Neumann, J. Am. Chem. Soc. 2004, 126, $10236-10237$.

[26] a) D. M. Robinson, G. M. Keating, CNS Drugs 2007, 21, 337-354; b) W. Schwarz, J. Schossig, R. Rossbacher, H. Höke in Ullmann's encyclopedia of industrial chemistry, Vol. 6, Wiley-VCH, Weinheim, 2000, pp. 457-463; c) K. Miltenberger in Ullmann's encyclopedia of industrial chemistry, Vol. 18, Wiley-VCH, Weinheim, 2000, pp. $481-492$.

[27] P. Atkins, T. Overton, J. Rourke, M. Weller, F. Armstrong, M. Hagerman in Inorganic chemistry, W. H. Freeman and Company, New York, 2010, pp. 787-799.

[28] C. Shen, E. A. Garcia-Zayas, A. Sen, J. Am. Chem. Soc. 2000, 122, 40294031.

[29] J. H. Lee, K. S. Yoo, K. W. Jung, Bull. Korean Chem. Soc. 2011, 32, 2881 2882.

[30] R. J. Lemire, U. Berner, C. Musikas, D. A. Palmer, P. Taylor, O. Tochiyama in Chemical thermodynamics of iron part 1, Vol. 13a, (Ed.: OECD Nuclear Energy Agency Data Bank), OECD Publications, Paris, 2013, pp. 234282.

[31] a) J. M. Casas, G. Crisóstomo, L. Cifuentes, Hydrometallurgy 2005, 80, 254-264; b) G. Yue, L. Zhao, O. G. Olvera, E. Asselin, Hydrometallurgy 2014, 147-148, 196-209.

[32] S.-I. Ohira, Y. Hiroyama, K. Nakamura, T. Koda, P. K. Dasgupta, K. Toda, Talanta 2015, 132, 228-233.

[33] a) A. S. Jhaveri, M. M. Sharma, Chem. Eng. Sci. 1967, 22, 1-6; b) J. A Keith, J. Oxgaard, W. A. Goddard, J. Am. Chem. Soc. 2006, 128, $3132-$ 3133; c) J. J. Dong, W. R. Browne, B. L. Feringa, Angew. Chem. Int. Ed. 2015, 54, 734-744; Angew. Chem. 2015, 127, 744-755.

[34] G. A. Truesdale, A. L. Downing, Nature 1954, 173, 1236.

[35] R. A. Periana, D. J. Taube, S. Gamble, H. Taube, T. Satoh, H. Fuhii, Science 1998, 280, 560-564.

[36] R. Palkovits, C. von Malotki, M. Baumgarten, K. Müllen, C. Baltes, M. Antonietti, P. Kuhn, J. Weber, A. Thomas, F. Schüth, ChemSusChem 2010, 3, $277-282$.

[37] S. R. Maqsood, N. Islam, S. Bashir, B. Khan, A. H. Pandith, J. Coord. Chem. 2013, 66, 2308-2315.

[38] U. Izawa, S. S. Stahl, Adv. Synth. Catal. 2010, 352, 3223-3229.

[39] M. B. Smith, J. March in March's advanced organic chemistry: reactions, mechanisms and structure, Vol. 6, Wiley, New Jersey, 2007, pp. 408.

[40] J. M. Rawson, R. E. P. Winpenny, Coord. Chem. Rev. 1995, 139, 313-374.

[41] A. Z. Michelson, A. Petronico, J. K. Lee, J. Org. Chem. 2012, 77, $1623-$ 1631.

[42] L. R. Holloway, L. Li in Nitrosyl complexes in inorganic chemistry, biochemistry and medicine II, (Ed.: D. M. P. Michael), Springer, Berlin, 2012, pp. 53-98.

[43] T. J. Ferris, M. J. Went, Forensic Sci. Int. 2012, 216, 158-162.

[44] T. Mallat, A. Baiker, Catal. Today 1994, 19, $247-284$. 
[45] J. H. Teles, I. Hermans, G. Franz, R. A. Sheldon in Ullmann's encyclopedia of industrial chemistry, Wiley-VCH, Weinheim, 2015, pp. 1-102.

[46] K. Weissermel, H.-J. Arpe in Industrial organic chemistry, Vol. 3, WileyVCH, Weinhein, 1997, pp. 207-208.

[47] R. J. Brotherton, H. Steinberg in Progress in boron chemistry, Pergamon Press, New York, 1970, pp. 3-21.

[48] M. Wang, Y. Zhang, M. Muhammed, Hydrometallurgy 1997, 45, 53-72.

[49] L. P. Méndez De Leo, H. L. Bianchi, R. Fernández-Prini, J. Chem. Thermodyn. 2005, 37, 499-511.
[50] S.-I. Imamura, T. Sakai, T. Ikuyama, J. Jpn. Pet. Inst. 1982, 25, 74-80.

Manuscript received: April 18, 2019

Revised manuscript received: June 3, 2019

Accepted manuscript online: June 6, 2019

Version of record online: July 9, 2019 